\title{
Specialization, semiosis, semiotics: the 33rd annual meeting of the Semiotic Society of America
}

\author{
Paul Cobley $^{1}$
}

The 33rd annual meeting of the Semiotic Society of America, 'Specialization, semiosis, semiotics', took place, this year, entirely in a hotel. The Renaissance Hotel, Houston is set on its own lot and, like Houston itself, is car-friendly but forbidding for pedestrians who might wish to gain access to any signs of life beyond its edifice. The 20th floor, where the proceedings took place, looks out across the endless suburbs of Houston and further, into the pancake flatness of Texas. Although the conference was this year run under the auspices of the University of St. Thomas, whose open, welcoming, campus was just a mile or so up the road, delegates found themselves thrown together for the duration, braving the sessions at the conference or the individually wrapped soaps in the air-conditioned atmosphere of their rooms. The disadvantage of having a conference in a hotel that I am pointing out here, of course, is that there is no escape. In that respect, the Renaissance was a bit like the Valtionhotelli in Imatra, Finland, where annual meetings of the ISI have forced conference - goers to either stay indoors and engage with each other or face a legion of mosquitoes and profound ennui. Like the Imatra meetings, however, this SSA conference made the disadvantage into a virtue and any perception of that disadvantage a lost figment of memory. It is a measure of the conference's success that the main complaint I heard and, indeed, voiced myself, was that there was too little time and that the conference was too short.

The meeting took place over four days, 16-19 October 2008. It featured 5 plenary addresses, two plenary roundtables and around 46 parallel sessions. In contrast to previous meetings, there was a strong biosemiotic strand in the

1 Author's address: Paul Cobley, London Metropolitan University, 31 Jewry Street, London EC3N 2EY, UK; email: p.cobley@londonmet.ac.uk. 
proceedings this year. These included two sessions on 'Biosemiotics': one featuring key international biosemioticians, Don Favareau, Jesper Hoffmeyer and Kalevi Kull, the other featuring Priya Venkatesan, Jennie Wojtaszek, Prisca Augustyn and Ted Baenziger. There were sessions on 'Biosemiotics and culture', 'Objects of desire, adventures in physiosemiosis and formal semiotics', a session on 'Abduction and culture' (which was largely biosemiotically inspired); and the biosemiotics plenary roundtable on definitions of semiosis which took place on Sunday morning (see Fig. 1). That two dyed-in-the-wool cultural semioticians, myself and Anne Hénault, were participants in the latter should indicate that biosemiotics' key importance is becoming palpable.

The other sessions were encouragingly varied. It is true that scattered across the programme were the odd semiotic analyses of advertisements or other media and literary artefacts in papers that have rather become the bread and butter of semiotics meetings. Yet, the diversity and rigour of the sessions and papers demonstrated the strength and new horizons of contemporary semiotics. Music remained well represented, whether it was Matthew Shaftel's paper on Ives, Vincent Colapietro's on psychoanalysis and jazz, David Lidov on the efficacy of Jakobson's functions, Scott Murphy on the echoes of Wagner in the music in Hitchcock's films, or the Presidential Address by Robert Hatten (Fig. 2) that treated the audience to some close analyses of Mozart (through singing and the piano) while acting as a prelude to Hatten's ballet, Swerve, performed at the University of St. Thomas on the Friday night.

A strong local presence was felt at the meeting, as might be expected. Undergraduates and postgraduates (as well as staff) of the University of St. Thomas acquitted themselves exceptionally well with thoughtful papers, expertly delivered. It should not need saying that this is where the future of semiotics, or any discipline lies: in the energy and new ideas of young scholars. A flavour of this is offered by John Deely's quoting in his plenary a student at the university who observed, refreshingly, that semiotics is the endeavour that studies all the things that other disciplines take for granted. This is a fresh, and very accurate, way to account for the diversity in the field that we know so well. But freshness also entails seeing the past with new eyes. I was interested to see the sessions on Thomist semiotics and on Carmelite semiosis, as well as a jointly-presented paper in another session on 'García de la Madrid: ideas and signs in the Iberian grey zone (1650-1850) that follows the Black Hole (1350-1650)'.

Fresh eyes projecting the past into the future were also complemented by more directly future-orientated sessions and papers. A session on 'Semiotics and philosophy' focused mainly on contemporary accounts of consciousness, including 'neuro-consciousness'; a session on empirical semiotics was focused on synaesthesia; one on myths of technology was sceptical about some futures laid out for us by nanotechnology and cyborg mythologies; 
while a session was also devoted to a topic which is of extreme interest even to the most committed atheist with an interest in what happens tomorrow as well as what happened yesterday: 'Theosemiotics: the study of the action of divine signs'.

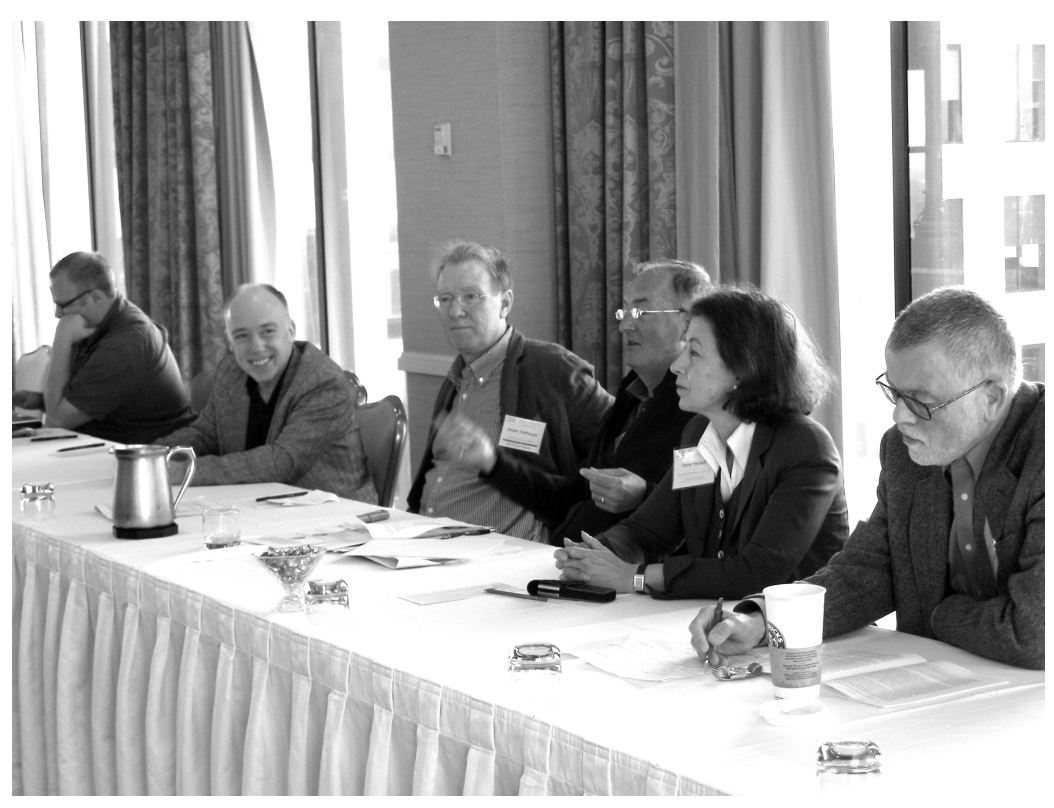

Figure 1. Roundtable panel 'Definitions of semiosis' on October 19, 2008. From right to left, Winfried Nöth, Anne Hénault, Peter Harries-Jones, Jesper Hoffmeyer, Donald Favareau, Paul Cobley. Kalevi Kull taking the picture.

The quality and tenor of many conferences, of course, are judged by one or both of two things: its keynote papers /plenary addresses; and its book exhibit. The latter featured mainly US publishers (understandably, given the distance from European centres of publishing), commercial and university presses and was very good. The new works for sale indicated a vibrancy and breadth of endeavour which was reflected in the conference itself; the books presented for exhibition indicated tradition and the scholarly virtues, from the dual-translation Poinsot volume to the Peirce editions. For those interested in book retailing facts, Hoffmeyer's new volume, Biosemiotics (University of Scranton Press), was the best seller, with all copies snatched up before close of business on the third day. 


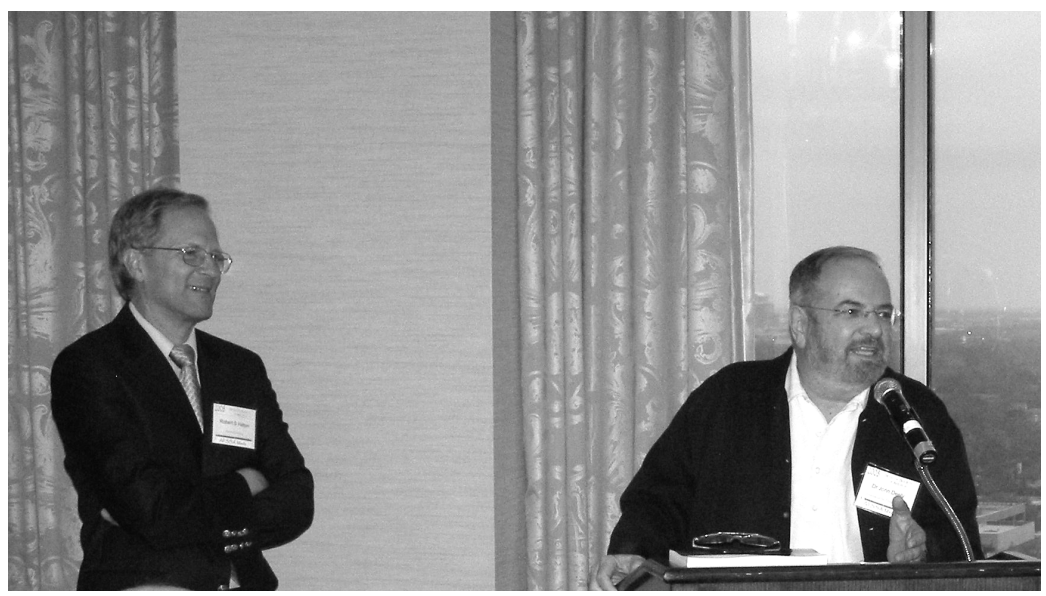

Figure 2. President of the SSA, 2008, Robert Hatten (left), and John Deely, at a plenary session.

The plenary papers implied issues of specialization, as in the title's conference, but were most explicitly concerned with the intricacies of semiotics and semiosis. Either by chance or by design, the four papers in addition to Hatten's address, complemented each other perfectly and foregrounded semiotics' teaching, in a pedagogical and in a social sense. Kalevi Kull's paper, 'Semiosis makes the world locally plural' gave an account of semiotic endeavour through the lens of the "original university semiotics program on planet Earth", stressing the plurality in the conference that was evident in the microsemiotics of papers such as Elena Yakovleva's 'A semiotic intercultural approach to the@ sign' and the macrosemiotics evidenced in Myrdene Anderson's and Devika Chawla's 'Nonlinear evolutionary living, linear developmental lives' and others. Susan Petrilli's plenary, inaugurating her as the SSA's 7th Sebeok Fellow, ${ }^{1}$ was concerned with the topic of semioethics, calling for dialogue and answer to the response of the other, as well as responsibility in the awareness - as only humans can have - of sign use. As such, her paper was about what she believes semiotics must teach the world at large. Deely's paper, on the other hand, while discussing 'the semiotic animal', was more tightly preoccupied with the actual conception of 'sign' and demonstrated that, despite semiotics sometimes being dubbed 'the study of the sign', we still have much to learn — and to teach — regarding what the sign relation entails. The theme

See Nuessel 2008. 
was continued on the Saturday evening as the University of St. Thomas staged, with two superb actors, a dramatic reading of Deely's 'A sign is what? A dialogue between a semiotist and a would-be realist', a text which keen readers of Sign Systems Studies will recognize as first having appeared in this journal (Deely 2001). My own plenary talk on 'Cultural implications of biosemiotics' was, characteristically, a sham, because it replayed or amplified, albeit self-consciously, the implications that Hoffmeyer had already cogently laid out in his 1996 book, Signs and Meanings in the Universe. However, it did strenuously seek to emphasize that we - the semiotics community - need to do more to make it generally known what a sea change in human understanding biosemiotics constitutes.

In one way, the intimacy of this conference reflected the fact that it is still a 'meeting' of a semiotic society. About 160 delegates attended and not only were they assembled for plenary sessions but meals were taken with all delegates together, in a room where the plenary papers were also given after or before the meals. On the other hand, intimacy should not be taken for closure or compartmentalization: over 20 different nationalities were represented at this meeting and the sheer diversity as well as the number of parallel sessions made it seem more like a well-organised IASS congress. My personal regret is that I did not have time to sit down and talk with so many friends and scholars and that I was unable to meet or have a prolonged conversation with as many of the people who were new to me as I would like. Also, I regretted having to miss some sessions while I attended other sessions. This was echoed by other delegates and it must be said that it is all too seldom the case that one encounters such sentiments at scholarly conferences. Under these circumstances, and in addition to the fact that there were no glitches, the organization of the meeting by Tom Broden of Purdue University and the local scholars, principally John Deely, went completely unnoticed — which is exactly how it should be. No greater testimony of the success of a conference can be given.

\section{References}

Deely, John 2001. A sign is what? A dialogue between a semiotician and a wouldbe realist. Sign Systems Studies 29(2): 705-743.

Hoffmeyer, Jesper 1996. Signs of Meaning in the Universe. Bloomington: Indiana University Press.

- 2008. Biosemiotics: An Examination into the Signs of Life and the Life of Signs. Scranton: University of Scranton Press.

Nuessel, Frank 2008. Susan Petrilli named seventh Thomas A. Sebeok Fellow of the Semiotic Society of America. Sign Systems Studies 36(2): 521-525. 
520 Paul Cobley 